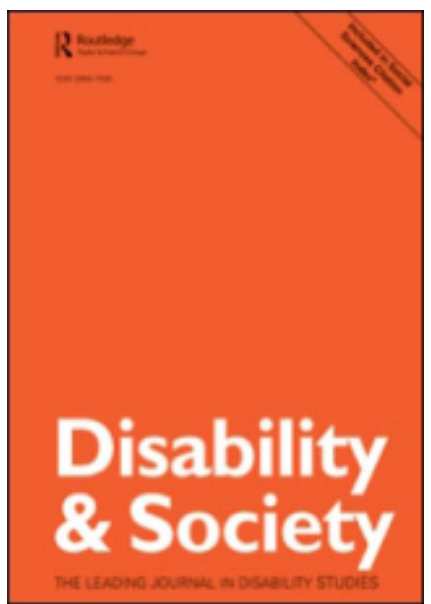

\title{
Feeling the Benefit? Fluctuating Illness and the World of Welfare
}

\begin{tabular}{|r|l|}
\hline Journal: & Disability \& Society \\
\hline Manuscript ID & CDSO-2019-0032 \\
\hline Keywords: & LUPUS, FLUCTUATION, WELFARE BENEFITS, WORK-BASED IDENTITY \\
\hline Abstract: & $\begin{array}{l}\text { This article explores the experiences of people living with fluctuating } \\
\text { long-term conditions, with a particular focus on the UK welfare benefits } \\
\text { system. Respondents in this study suggested that this system } \\
\text { constitutes a critical barrier to maintaining a positive work-based } \\
\text { identity, being characterised by assessment and decision making } \\
\text { processes that are inappropriately focused and inflexibly implemented. } \\
\text { Here we report the findings from a cross sectional online study of people } \\
\text { aged } 18 \text { to 75+, resident in the UK, with a self-reported diagnosis of } \\
\text { lupus, arguably, the archetypal fluctuating condition. We explore some of } \\
\text { the key themes respondents living with lupus identified in the context of } \\
\text { striving to maintain a sense of themselves as productive and functional } \\
\text { citizens. We conclude that there is a critical lack of attention afforded to } \\
\text { the experience of fluctuating illness within the State benefits system and } \\
\text { offer some strategies for better understanding, and addressing, this } \\
\text { issue. }\end{array}$ \\
\hline
\end{tabular}

\section{SCHOLARONE Manuscripts}

This is an Accepted Manuscript of an article published by Taylor \& Francis in Disability and society on 31 Oct 2019, available online: http://www.tandfonline.com/10.1080/09687599.2019.1680346 
Feeling the benefit: Fluctuating illness and the word of welfare

Points of interest

- This article explores the welfare benefits experiences of people living with fluctuating illness

- The research was undertaken with people living with lupus, which is a condition that appears to 'come and go'

- Participants in the research said that their experience of the benefits system was stressful, largely because the system doesn't accommodate illnesses in which, on some days, the person is able to work whilst, on others, they are not

- Some people chose not to apply for any sort of benefit because of these issues and because of the stigma that is still attached to claiming State support

- One way to address some of these problems might be to think about fluctuating illness in the way that disability is understood 


\section{Feeling the Benefit? Fluctuating Illness and the World of Welfare}

\section{Introduction}

Contemporary public policy in the UK is increasingly concerned with enabling, maintaining, and supporting stable paid employment for people living with long-term illness and disabilities. This focus is married to a concomitant, though largely implicit, policy driven commitment to limit access to increasingly scarce public funds. Indeed, at the time of writing, the UK Government is implementing amendments to State Benefit rules and regulations which will replace a raft of State support with one overarching benefit 'Universal Credit'. Variously perceived as long-overdue reform and a 'social catastrophe' (Harris, 2017), the concept of Universal Credit is indicative of the UK Government's priority to limit State support to the extremes of need. Similarly, sickness benefits are also undergoing fundamental change resulting in an increasingly narrowly defined and operationalised framework for entitlement. This paper presents a timely analysis of the experience of living, uncertainly, on the margins of this State support system. We focus, on people who live with fluctuating chronic illness (specifically lupus), many of whom will live, for many of their adult years, reliant on a benefits system that does little to recognise the particularities of their conditions or its pervasive effects.

Paid employment is recognised as pivotal to individual and societal well-being (Foubert, et al., 2016) offering economic, material and psychosocial benefits which enable full participation in society. Conversely, there are obvious and clear associations between unemployment and higher mortality and poor mental and physical health (Waddell and Burton, 2006). The evidence is clear that, for those people who access State support in the absence, or restriction, of paid employment, there are clearly evidenced (Allen, et al., 2016; de Woolfe, 2010; Garthwaite, 2014; Pickles, et al., 2016;) indicators that long-term reliance on State benefits, and a lack of support to enable people back into the workplace, is counter-productive, not only in terms of well-being but also, as we will argue below, in the context of a potential loss of skills and experience in the workplace. Indeed, UK government figures suggest that of the people who rely on sickness benefits only $1-2 \%$ leave the benefits system for reasons other than retirement or death (Pickles, et al., 2016). Successive governments have sought to address this issue and welfare reform, in the UK at least, is evidenced by incremental shifts towards an explicitly neo-liberal model in which the notion 
of 'welfare' has gradually been replaced by that of 'workfare' and, in the context of welfare benefit entitlement, a determined focus on targeted and conditional entitlement (Bambra, 2008; Bambra and Smith, 2010).

The experience of reliance on State support has been reported as overwhelmingly negative, with assessment and decision making processes being inappropriately focused and inflexibly implemented (see, for example, Allen, et al., 2016; de Woolfe, 2012; Garthwaite, et al., 2013; Muscular Dystrophy UK, 2016; The majority of these examples, however, report on the experiences of people with long-term conditions and disabilities which are either stable in their effects or are evidenced by demonstrable progression and deterioration. There is little research which has addressed the workplace, or benefit related issues, faced by people who experience relapsing, remitting and fluctuating conditions. Much of that which does exist is anecdotal, with data being collected and reported largely online (Disabled People Against Cuts, 2017; Commons Select Committee, 2017). Notable exceptions, however, include Allen, et al., (2016) whose work explores the experiences of people with myalgic encephalomyelitis. Even the recent White Paper (Doh/DWP, 2017), whilst putting forward proposals to increase employment opportunities and outcomes for people with long-term conditions, made no mention of the ways in which fluctuating conditions might be accommodated or managed. Guidance on the ways in which employers should adapt working environments and the support that might be offered to people in these contexts to enable them to continue to work effectively was similarly absent (Booth, Price and Walker, 2018).

This paper contributes to the small, but growing, literature which focuses on the experience of claiming State benefits for people, in the UK, living with conditions that are defined and exemplified by their fluctuating nature. Here, we focus specifically on lupus, arguably the archetypal relapsing and remitting condition. Lupus is a disabling condition which characteristically affects people in their most productive working years and can have a profound effect on their educational and employment opportunities. This, in turn, can impact negatively on quality of life and lifetime opportunities. We employ lupus as an exemplar, and an illustrative case study, here as it affords a very particular lens with which to explore the experiences of navigating the contemporary welfare benefits system. It adds significantly to the limited literature identified above. Lupus is one of a wide range of 
autoimmune conditions (where the immune system perceives normal body tissue as pathogenic) in which the immune system produces antibodies which negatively affect the normal processes of internal organs and the skin. Given that it is a systemic condition (meaning that its effects are felt throughout the body), the symptoms of lupus are not necessarily similarly evident in every person and it is experienced differently depending on the particular part of the body affected at any one time. One of the defining features of lupus, however, in addition to the wide variety of symptoms, is the way in which the symptoms, and their effects, can shift and change, sometimes in the space of hours or days. Lupus has been referred to as 'the great mimic', often being mistaken for other conditions and, as such, people with lupus find themselves negotiating multiple medical specialisms and consequently frequently have to wait extended periods of time for a definitive diagnosis (Stockl, 2007; Price and Walker, 2014). In short, lupus is a condition "uniquely characterised by symptomatic uncertainty, fluidity and continual flux and change" (Price and Walker, 2015:34). It is the defining features of lupus which posit the condition as fundamentally at odds with the reportedly inflexible manner in which the contemporary benefits system operates. An examination of lupus, therefore, throws into sharp relief the limitations of the benefits system in the context of managing long-term conditions which, as we note above, are defined by their fluctuating course and effects.

We contend that our exploration of the ways in which the shifting experience of lupus shapes people's experiences of state welfare benefits allows for a more generalised understanding of the ways in which the welfare benefits system is experienced by those people who have similarly 'non-linear' long-term conditions, such as Rheumatoid Arthritis, Multiple Sclerosis, Scleroderma etc. We argue that there are unique dimensions to the experience of living with State support with a condition which is neither fixed nor, necessarily, visible, yet, significantly disabling, which can propel the person between the semantic poles of 'deserving' and 'undeserving' claimant, impelling an acute awareness of the importance of accurately performing both the ill (and the well) body for the purposes of external assessment.

We explore some of the key themes respondents living with lupus identified in a cross sectional online study: the impact not being in paid employment has on wellbeing and the ways in which people experience the transition from work into welfare; the ways in which 
the body is necessarily displayed and performed in order to satisfy contemporary welfare benefits criteria and, in the face of sometimes overwhelming challenges, the ways in which people strive to maintain a work-based identity and a sense of themselves as productive and functional citizens. In conclusion, we advocate for a re-engagement with the debate around chronic illness and the social model of disability and argue for a more evident and effective articulation between the workplace and the benefits system for people living with fluctuating conditions. Our principle concern is to highlight the very real potential for the skills and attributes of this group of highly educated, qualified and experienced people to be never realised or prematurely lost and to clearly articulate how this impacts upon individuals' mental and physical well-being.

\section{Illness Identities and the World of Welfare}

The experience of living with a chronic illness has generated an extensive literature which has focused, variously, on the profound disruption to a life trajectory that illness generates (Bury, 1982; 1991); Charmaz, 1983; Carel, 2008; Williams, 2000) and the impacts and burdens illness presents, particularly during what are generally perceived to be a person's most productive working years (Anderson and Bury, 1988; Miles, 2013; Price and Walker, 2015; Stockle, 2007). Less well explored, however, are the particular experiences of those people with long-term conditions who rely on support from the welfare benefits system - a surprising omission, given the myriad difficulties living with support from the welfare benefits system can present and the fact that relying on welfare benefits can be a central and defining feature of living with a long-term condition (de Woolfe, 2012; Garthwaite, 2014). The small body of work that does exist contests the popular view that living a life on benefits is an 'easy option' for the 'workshy' (de Woolfe, 2012; Garthwaite, 2011), effectively charting the journey an individual undergoes in the transition from an identity as 'worker' to that of 'benefit claimant'. It is in this process of a shifting sense of self that the stress and anxiety associated with applying for, and living in receipt of, welfare benefits is perhaps most acutely felt. Surprisingly, this shift in anticipated biographical trajectory has also received relatively little attention (Garthwaite, 2015; Riach and Loretto, 2009; Wainwright, et al., 2012), but it is precisely the disruption and reconstitution of self in the face of a shifting professional identity that was strikingly apparent in our own data. 
It is the complex assessment processes embedded in the contemporary welfare benefits system which are often cited as the primary reason why people find claiming welfare benefits so uniquely distressing. For people who are unwell, the additional stresses and strains associated with a benefit claim can add an unwelcome additional burden which can generate an iatrogenic response to the process (Allen, et al., 2016; de Woolfe, 2012; Garthwaite, 2014; Illich, 1974). Indeed, some of the respondents in de Woolfe's (2012) study, stated that "the difficulties of being a claimant outweigh all other negative aspects of illness experience" (p.622). The process of claiming benefits was suffused with anxiety and stress and the fear of increasing surveillance, and an associated sense of illegitimacy, impacted negatively on people's sometimes very fragile self-esteem. Respondents in de Woolfe's (2012) study stated that they felt systematically disenfranchised and stigmatised by a system which 'conveys the message that ongoing and progressive illness should present no permanent barrier to a working life' (p. 627). This message was amply reflected in the UK Government's focus on streamlining the disability benefit bill in 2013, when Esther McVey, Minister for Disability famously stated that "Only three per cent of people are born with a disability, the rest acquire it through accident or illness, but people come out of it. Thanks to medical advances, bodies heal" (Mail Online, 2013). Similarly, Garthwaite (2014) highlighted the fear that applying for, and receiving, welfare benefits can generate for people living with long-term health problems. For some people, this fear and anxiety was so acutely felt that it led to suicide. Garthwaite's work also highlights the ways in which the semantics of welfare reform are finely crafted to reify a caricature of dependency designed to stigmatise and further segregate 'undeserving' claimants (Garthwaite, 2011; 2015). Both de Woolfe (2012) and Allen, et al., (2016) focus on the experiences of people living with Myalgic Encephalomyelitis (ME), a condition characterised by its fluctuating and uncertain symptom trajectory and prognosis. It was this defining feature of the condition which assessors for benefits claims were unable (or unwilling) to take into consideration. Instead, they applied a snapshot blanket assessment of functional capacity which may, or may not, occur on a 'good' or 'bad' day for the person concerned.

Given the lack of credence (at both individual and policy levels) afforded to the experience of fluctuating conditions, the contemporary sickness benefits system would appear to be predicated upon an outdated articulation of the sick role. Though people with long-term 
conditions, such as lupus, will not regain good (even less full) health, there is a policy driven expectation that people will at least strive to make this happen. The implicit message being, as it always was in the original Parsonian (1951) definition of the sick role, that it is one's civic responsibility to 'get better' and to overcome the limitations posed by illness. Nettleton (2013:72) suggests that even "where people are not blamed for the onset of the condition, there is an expectation that people should do what they can to get better. A positive personality and creative response to disease is triumphed". In this context, where illness is understood as necessarily time-limited (unlike 'disability' which is more often seen as lifelong and unremitting), it is difficult to create a space in which to situate conditions which fluctuate both in their symptomatology and impact.

The State framework for managing sickness and disability benefits currently includes the Personal Independence Payment (PIP), Attendance Allowance and (Employment Support Allowance (ESA). ESA is gradually being replaced by Universal Credit (UC). For those of working age, these benefits constitute the majority of long-term sickness claims (Pickles, 2016). They each require a range of external assessment to determine eligibility, including a Work Capability Assessment (ESA and UC) and an assessment of "how your disability affects you' (PIP). The change to PIP from its previous incarnation, Disability Living Allowance (DLA), in April 2013, was predicated upon a Conservative Government commitment to better target sickness benefits to those who needed it most. In practice, as we will demonstrate below, the net result has been to make the benefit more difficult to claim for anyone but those with the most severe physical and psychological disabilities. Unlike DLA, eligibility for PIP is based upon an external assessment with regular assessments of continuing eligibility (generating, for many people, an unwelcome additional source of unpredictable stress). Eligibility is based upon a series of tests that include preparing and eating food, managing medication, maintaining personal hygiene and making day-to-day decisions. Points are awarded for each activity and the level of benefit determined upon the score. Claimants are required to have needed assistance for more than three months to qualify and the expectation is they are likely to maintain that requirement for at least nine months into the future (Gray, 2014; Gray, 2017). This most basic articulation of this claim process clearly suggests that it is best suited to either stable conditions of those whose course is exemplified by ongoing deterioration, though recent reports in the popular press 
would suggest that even under these conditions, people experience the benefits system as an unremitting 'hostile environment' (Butler, 2018) in which it is impossible to fairly access State support. Respondents in our study would firmly underline this view.

\section{Methods}

Here we report the findings from a cross sectional online study of people aged 18 to 75+, resident in the UK, with a self-reported diagnosis of lupus (ethical permissions were granted by the University of Hull Faculty of Health Sciences Ethics Committee). The survey was created using the Bristol Online Software (BOS) and was posted on LUPUS UK's website and Twitter from 2nd September - October $31^{\text {st }} 2017$. All responses were anonymous. Following BPS (BPS, 2017) guidance on conducting online research, respondents were strongly encouraged not to include any identifying information in answers to questions; respondents were provided with a direct link to a list of support services, they were informed as to how the data collected would be used and were required to tick a box indicating that they has read and understood the information provided before they could proceed to completing the questionnaire.

The qualitative survey consisted of 22 questions: 9 were demographic, including one on drug therapy. 15 were stem questions where a quantitative response was required with an opportunity for a free text statement. Ten stem questions related to employment, two specifically to the benefits system. The topic areas to be covered were developed in consultation with members of the Cambridgeshire Lupus Support Group.

A range of demographic data was collected, including education, occupation and employment status. Participants were asked about the understanding shown by their managers and colleagues about their illness and its day to day fluctuations and to quantify (with numerical rating scales) the psychological distress associated with (i) loss of income resulting from lupus, (ii) the proportion of income loss due to SLE (iii) the degree of fear that participants experienced about being unable to sustain future employment and (iv) experiences of the benefits system. The employment data is reported elsewhere (Booth, Price and Walker, 2018). 
Descriptive statistics summarise respondent characteristics and frequency of responses. Thematic analysis (Braun and Clarke, 2008) of free text comments was conducted independently by all authors, then compared, agreed and summarised.

One of the limitations of online research is that it can exclude certain groups of people who have limited access to, or familiarity with, the technologies required to take part. Nonetheless, the anonymity offered by the technology can provide a point of access to research such as this for hard to reach groups, particularly in the context of stigmatised illnesses (Price and Walker, 2015). In addition, online research can offer an avenue and forum for the articulation of views not heard, understood or supported elsewhere. We would argue that this research methodology constitutes a tool through which people who are disenfranchised are able to articulate their views. In this context, we were overwhelmed by the speed and number of responses to the questionnaire, which was posted online between 2 September 2017 and October 31 2017.

Online research can be less time consuming for respondents as they are able to undertake at their own convenience and the method has been cited as a way to reduce interviewer bias. However, the use of online data sources does not permit for clarification of meaning and there may be high attrition rates (Walker, 2017).

There is no duplication of respondents in the quotations provided below.

\section{Participants}

Over a period of 8 weeks, 393 people responded to the survey. The majority of respondents completed the survey in the first two weeks of its publication, demonstrating their eagerness to share and articulate their experiences.

\begin{tabular}{|c|c|c|c|c|c|c|c|}
\hline \multirow[t]{3}{*}{ Age } & $18-24$ & $25-34$ & $35-44$ & $45-54$ & $55-64$ & $65-74$ & $75+$ \\
\hline & 15 & 84 & 117 & 114 & 57 & 4 & \\
\hline & $3.8 \%$ & $21.5 \%$ & $29.9 \%$ & $29.2 \%$ & $14.6 \%$ & $1 \%$ & \\
\hline \multirow[t]{2}{*}{ Gender } & \multicolumn{2}{|c|}{ Male } & \multicolumn{2}{|c|}{ Female } & Agender & \multicolumn{2}{|c|}{ Prefer not to say } \\
\hline & \multicolumn{2}{|c|}{$10-2.6 \%$} & \multicolumn{2}{|c|}{$381-97.2 \%$} & $1-0.3 \%$ & \multicolumn{2}{|c|}{0} \\
\hline
\end{tabular}




\begin{tabular}{|c|c|c|c|c|c|c|c|c|c|c|c|c|}
\hline \multirow[t]{2}{*}{ Education } & \multicolumn{2}{|c|}{ GCSE } & $\begin{array}{c}\text { A } \\
\text { Level }\end{array}$ & \multicolumn{2}{|c|}{ HND } & Degree & \multicolumn{4}{|c|}{ Post-grad } & \multicolumn{2}{|c|}{ other } \\
\hline & \multicolumn{2}{|c|}{98} & 40 & \multicolumn{2}{|c|}{59} & 116 & \multicolumn{4}{|c|}{90} & \multicolumn{2}{|c|}{26} \\
\hline \multirow{2}{*}{$\begin{array}{l}\text { Ethnic } \\
\text { group }\end{array}$} & $\begin{array}{l}\text { Black } \\
\text { British }\end{array}$ & $\begin{array}{c}\text { Black } \\
\text { African }\end{array}$ & $\begin{array}{c}\text { Black } \\
\text { Caribbean }\end{array}$ & $\begin{array}{l}\text { Other black } \\
\text { background }\end{array}$ & $\begin{array}{l}\text { White } \\
\text { British }\end{array}$ & $\begin{array}{l}\text { Other white } \\
\text { background }\end{array}$ & Asian & $\begin{array}{l}\text { Asian } \\
\text { British }\end{array}$ & Chinese & Arabic & $\begin{array}{c}\text { Dual } \\
\text { heritage }\end{array}$ & Other \\
\hline & 7 & 1 & 5 & 0 & 330 & 19 & 4 & 11 & 3 & 0 & 7 & 5 \\
\hline \multirow[t]{2}{*}{$\begin{array}{l}\text { Length of } \\
\text { Diagnosis }\end{array}$} & \multicolumn{2}{|c|}{$\begin{array}{c}\text { Less than } \\
1 \text { year }\end{array}$} & & \multicolumn{2}{|l|}{$1-5$} & $6-10$ & \multicolumn{3}{|c|}{$11-15$} & \multicolumn{3}{|c|}{$15+$} \\
\hline & \multicolumn{2}{|c|}{$\begin{array}{c}11 \\
(2.8 \%)\end{array}$} & \multicolumn{3}{|c|}{$\begin{array}{c}146 \\
(37.2 \%)\end{array}$} & $\begin{array}{c}97 \\
(24.7 \%)\end{array}$ & \multicolumn{3}{|c|}{$\begin{array}{c}41 \\
(10.5 \%)\end{array}$} & \multicolumn{3}{|c|}{$\begin{array}{c}97 \\
(24.7 \%)\end{array}$} \\
\hline
\end{tabular}

\section{Findings}

\section{Navigating the Geography of Contemporary Welfare}

Given the seriousness of a lupus diagnosis and its impact upon people's ability to maintain full-time paid employment, a surprising number of respondents to our survey did not claim welfare benefits (67\%). Many people chose, or were impelled, to manage without State support, despite the impact of their ongoing illness related problems. This was for a number of reasons including stigma, the meaning of disabled identities, the complexity of the system and the traumatic assessment process. In the first instance, for many respondents, it was the stigma associated with claiming welfare benefits that was a very evident deciding factor in their decision. In the context of concerted efforts to challenge the stigma associated with claiming State support, It is remarkable just how tenacious this stigma remains, despite the strength and power of the disability movement that has systematically challenged dogged perceptions of 'benefit scroungers'

I WILL NOT claim benefits no matter what... (Female 35 - 44; SW England; 1-5 years since diagnosis).

Nothing has ever been offered in the 4 years since my diagnosis. I have never asked for any form of sick note etc either. Partly as I believe it to be distasteful by 
upbringing and also in part that it would be a battle that I have no strength to fight (Male; 25-34; 1-5 years since diagnosis).

Respondents also articulated a presumed ineligibility for welfare benefits, having internalised an implicit understanding that, in order to do so, one is required to accurately exemplify a bona fide 'disabled' status. This status, however, is poorly defined, demonstrating both the semantic and political challenges associated with aggregating longterm illness and physical and psychological disability in both the personal and public consciousness (Barnes and Mercer, 1996; de Woolfe, 2002; Ravetz, 1998; Swain and French, 2000). Many respondents did not perceive themselves to fall into the social category 'disabled' - that is, their sense of their illness does not match their perception of what it means to be 'disabled', suggesting that the term itself is tenaciously limited to concrete articulations of physical impairment/infirmity.

\section{I haven't claimed as I wouldn't get anything. Because I don't always need looking after and sometimes I live an almost normal life, I wouldn't be seen as 'disabled' enough. However, I can be very ill for days or weeks at a time so I certainly couldn't hold down a job (Female 45-54; NE England; 1-5 years since diagnosis).}

This woman neatly summarises the conundrum facing many respondents, it is one which is fundamentally at odds with the political and social models of disability as much as it is at odds with the benefits system which, as we noted earlier, appears to operate best at the extremes of need.

I have been told I am too healthy to claim benefit for my lupus. This is despite the fact that some days I am incapacitated by migraines, fatigue and joint pain. I do not experience these symptoms enough apparently to warrant government support (Female 25-34; London; 1-5 years since diagnosis).

I applied but was turned down due to "not being ill enough". My experience of the benefit process was incredibly negative (Female 25 - 34; Midlands; 11-15 years since diagnosis).

For many respondents, the overriding imperative was to remain in work, in whatever form possible (again challenging popular notions of benefits claimants), but the complexities of 
continuing to work whilst attempting to access State support was a very evident disincentive to making a claim. Respondents thus variously managed their working lives to accommodate their illness, including working part- time, without recourse to additional State support.

I haven't bothered applying. I prefer to work, even if in a limited capacity (Female; 45-54; Midlands; 6-10 years since diagnosis).

What many respondents forcibly articulated was a drive and desire to attain paid employment and remain in work for as long as possible. No one saw State support as a viable or desirable alternative to paid employment. One young respondent was, in fact, evidently dismayed at the nihilism evident in the support she was variously offered.

It concerns me that from a very early age (when I was incorrectly told I had ME/ CFS) that I shouldn't continue with A levels or expect to go to university as I more than likely would never hold down a job. When asked how I am feeling at doctors/ specialist appointments the first "support" I'm given is the option to be signed off work. It worries me that health services are not encouraging employment. I think being is work should be encouraged. It provides you with a community, a sense of achievement and allows you a life beyond your illness (Female 45-54; South East England; 6-10 years since diagnosis).

For those who did claim sickness benefits, a clear majority reported the experience as extremely stressful, complex to navigate and demoralising. We asked participants to quantify (on a scale from 0 to 10 , with 10 being the maximum possible stress) how difficult or stressful they found the experience.

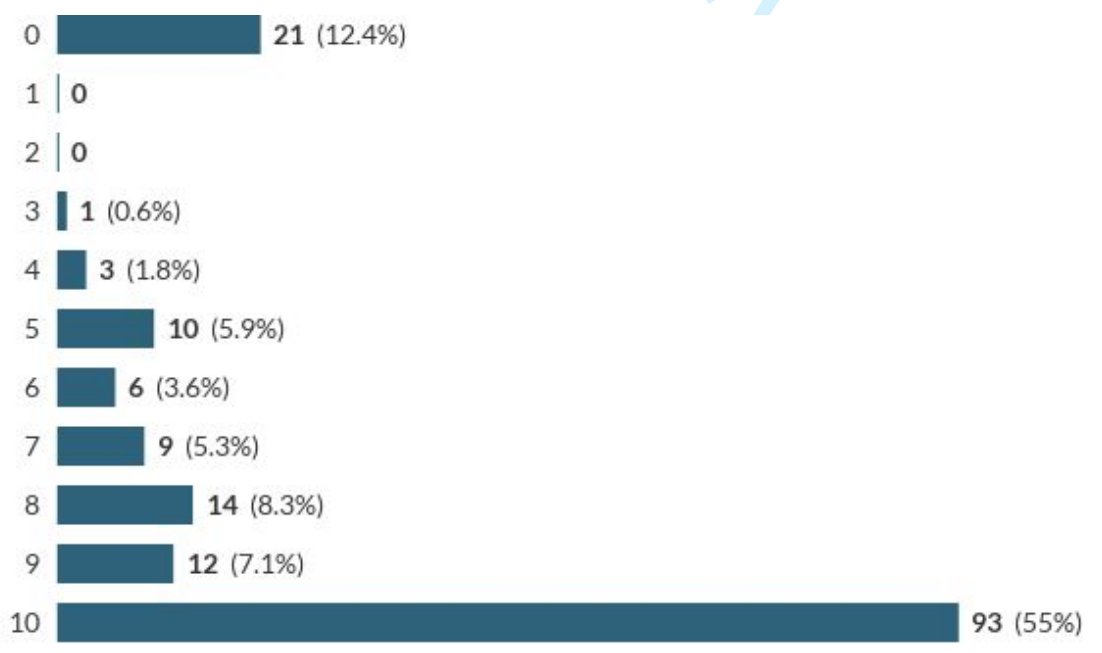


These figures were mirrored in the daily experiences people related to us. We use the following lengthy narrative as an exemplar, as it accurately reflects many respondents' narratives. We include this narrative in full in order to purposefully foreground the unabridged voices of respondents.

I was due to be reassessed for PIP in May 2016 but I had to go into hospital for open heart surgery to replace my aortic heart valve (lupus related). Because I was in intensive care I could not attend the Capita medical assessment and even though my family informed Capita and offered to send proof I was in hospital they sent three appointments and then sent my file back to the DWP stating that I had 'refused to attend' and on 1st August 2016 my PIP payments were stopped. I had to fight to get them back and then on 13th September 2016 I had a Capita medical assessment when I had only been out of hospital for 8 weeks after my heart operation and having collapsed lungs, an allergic reaction to warfarin, and costochondritis. The Capita medical assessor lied in her report, she made false statements, contradictions and even put that I was on blood thinning medication for a 'shoulder injury' instead of open heart surgery. My PIP was reduced from enhanced for both care and mobility to just standard care and no mobility. At the time I needed 24 hour care and had no money to pay for it so I had to cancel all my carers and even though my friends and family tried to help they were not able to do much for me and I was suicidal because of not knowing if I would ever get the help I needed and not having the strength to do anything about it... I felt like a burden to my friends and family and thought they would be better off without me. I had been referred to the mental health liaison team prior to leaving hospital and had to agree to weekly counselling because I had severe depression, anxiety and social anxiety... this was diagnosed on 5th July 2016 and the Capita medical assessor was shown all the paperwork yet she stated in her report that my mental health was 'unremarkable' ! I put in for a mandatory reconsideration but still did not get my PIP reinstated back to enhanced for both care and mobility... I just got standard for both. So I went to a tribunal which was on 5th May 2017 and was awarded more than double the points I had been from both the medical assessment and the mandatory reconsideration and I was awarded 20 points for care and 16 for mobility.... instead of 8 and 4 then 8 and 8 that I had previously been 
awarded. All this fighting made my depression worse and the senior clinical psychologist who I still see for counselling has stated that the DWP and Capita have traumatised me by making me go through my illnesses in such detail and having to fight for my PIP at a time when I should have been concentrating on recovering from major heart surgery. I have put in a complaint to both Capita and the DWP and the Independent case examiner is now chasing this as although Capita have admitted that one of their reports was 'not fit for purpose' the DWP have not got back to me.... I received a letter from them on 26th July 2017 stating they would get back to me within 3 to 4 weeks... and it is over 11 weeks now and I still have not heard from them (Female; 45-54; Wales; 15+ years since diagnosis).

\section{Fluctuating Entitlement and the Art of Assessment}

What the previous narrative forcibly demonstrates are the profound power imbalances embedded within the system of both application and assessment and the relative powerlessness of the claimant in the face of such overwhelming illness and inequity.

Tried to apply for PIP, but when attended medical was refused, as he put his own answers rather than what I had said. For example "can you cook a simple meal for yourself without help"? Me - "can't stay awake/alert to use cooker, can't smell, so don't know when things are burning/on fire, can't chop things up open tins or jars and can't stand up in the kitchen for any length of time". His answer was 'can cook a basic meal' (female; 35-44; Southwest England; 1-5 years).

The face-to-face assessment for PIP was horrendous; it was a year ago now and when I think of it I still feel tearful. The assessor was brutal and had already decided what to put. What I said made no difference (Female; 45-54; London; 15+years). I dread my reassessment in two years after the utter torture I went through. The assessors were horrible, the tribunals were unfair (I work in the real courts and they were breaking all the rules!) I felt like a fraud and a failure. I tried to end my life when I was refused the second or third time. I'll never forgive them for what they put me through (Female; 18-24; Scotland; 1-5 years since diagnosis). 
It is little surprise, given the trauma outlined above, that people are reluctant to seek State support and these experiences were not unusual in our online questionnaire, where many respondents' narratives very much echoed the experience of other people in different illness contexts who have noted the paradoxical iatrogenic effects and consequences of the sickness benefits system in the UK (Allen, et al., 2016; de Woolfe, 2012; Garthwaite, 2011, 2014, 2015; Wainwright, et al., 2012).

Claiming benefit is often more stressful than the disease itself. I know what to expect from Lupus, the same cannot be said for claiming ... The most worrying time of my life was being assessed for benefits! Having lupus is hard enough, without the threat of being homeless (Female; 35-44; London; 15+ years since diagnosis).

What is clearly evidenced in the narratives of these respondents is a shifting and uncertain sense of entitlement which is threaded through the benefits application process and, concomitantly, through respondents' own sense of themselves as worthy of financial support. There is, of course, a rich seam of literature which speaks to the uncertain social status of those people who claim long-term sickness benefits (see, for example, Garthwaite, 2011, 2014, 2015; Garthwaite et al.,2014; Bambra and Smith, 2010; Warren, et al., 2014). This is a body of work which does not, however, focus on the particular experience of a fluctuating condition, such as lupus, in which the sense (in both personal and policy contexts) of one's 'deserving' and 'undeserving' (Bambra and Smith, 2010; Garthwaite, 2014) status can similarly variously and unpredictably shift and fluctuate in tandem with the course of the condition.

When I'm off work, the process is so long, I decided to not process my disability claim. One of the things they ask is 'can you work today?' Meaning, if I am able to do work today, I cannot claim, but if I am unable to work next week, I have to wait until then to make a claim. The fact that I don't know when I will flare and considering my medications are failing at the moment it is hard to distinguish when I can and can't work. By the time a claim has gone through, my circumstances change (Female; 25 34; Northwest England; 1-5 years since diagnosis).

I applied for support, but was told I was ineligible as my illness doesn't affect me every single day (Female; 35-44; NE England; 6-10 years since diagnosis). 
Respondents were, thus, impelled to chart the complex and uncertain personal and political terrain between the poles of 'deserving' and 'undeserving', depending on illness status, their perceived eligibility being mirrored in explicit judgements made about the legitimacy of lupus itself, with the condition's defining features promulgated as additional evidence of an inauthentic illness experience.

My DWP Work Coach believes SLE is a phantom illness. When I said I was awaiting the results from my regular monitoring blood tests - 'special blood test' - she mocked me. Astonishingly, she said the Jobcentre does not seek confirmation of health conditions from the NHS (Female; 45-54; Scotland; 15+ years since diagnosis). They can't see Lupus, don't know what it is and don't care! (Female; 55-64; NE England; 15+ years since diagnosis).

As the two quotations above suggest, it was in the context of 'seeing' and recognising lupus that many respondents situated their experience of the sickness benefits system. Lupus is a largely hidden condition, the symptoms and impacts of which are not always immediately obvious to others. This aspect of the condition, and the ways in which people present themselves in the context of welfare benefits applications, is very much at odds with a system which is contingent upon applicants' ability to present as a bona fide, believably, 'ill' person. That is, one who performs their illness in a satisfactory way.

Support was declined. My symptoms were okay at the time. So they didn't see me at my worst. I didn't apply again (female; 35- 44; East of England; 11-15 years since diagnosis).

In this context, the system is clearly weighted against those who, one day, may be completely incapacitated by the condition whilst, on another, might be better able to manage the daily tasks of living. Many of the respondents in our online questionnaire, being patently unaware of the requirement to generate a very particular presentation of the self (Goffman, 1990), inevitably fell foul of the implicit, and unacknowledged, rules which underpin a successful benefit claim. 
Made to feel like benefit cheat as 'look well' and can do lots of things some of the time (female; 55-64; North-East England; 11-15 years since diagnosis).

You are made to feel like you are faking your illness when filling out the application forms and when being assessed. Basically treated like a liar (Female; 35-44; London; 11-15 years since diagnosis).

What these two quotations demonstrate is the profound, though arguably implicit, existential threat claiming benefits with a fluctuating condition can present to a person's sense of self and their integrity. Being made to feel like a 'cheat' and a 'scrounger' were common themes in respondents' narratives, yet the profound injustice, and irony, of the situation is clearly reflected in the fact that one of the overriding issues people focused on in their responses to the online survey, was their desire and willingness to fully participate, and maintain a productive presence, in the workplace. What was also very evident, however, was the fact that a significant majority of respondents' employers were evidently unable to accommodate the fluctuating nature of lupus and its impact in the workplace. As such, medical retirement and dismissal were common elements of respondents' narratives. The daily threats to maintaining employment and the resulting precarious nature of employment status was an added stress which many respondents felt unable to control or manage.

\section{I am scared that I will lose my job due to my lupus flares and being unable to work and fulfil my duties - I'm scared I will be medically retired or dismissed on capability grounds (Female, SW England, 55-64, 6-10 years since diagnosis).}

The anxieties this woman clearly articulates are well-founded and are often replicated in our data. When asked if they had left paid employment due to lupus, $21 \%$ (n84) of respondents stated that they were either were medically retired (11\%) or dismissed (10\%). $15 \%$ of respondents (n58) stated that they felt impelled to resign their post due to the effects of illness.

In such a highly educated and experienced group of respondents (48\% of respondents were educated to at least first degree level, with $21 \%$ of respondents having a post-graduate 
degree), the loss to society (and, of course to the individual), whilst difficult to quantify, is nonetheless very evident. This loss, of course, is both extant and potential - many of the young people who responded to our questionnaire reported the fact that they had been denied opportunities due to their illness married to an inflexible State support system which patently fails to enable them to negotiate future opportunities and possibilities.

In this context, many respondents articulated a profound fear of the future with its attendant uncertainty in respect of employment and/or the possibility of requiring State support.

The fear of losing your job and income when you have a flare up consumed my life at times. My manager put constant pressure on me to retire which I didn't want to do. This caused low mood and great anxiety. I couldn't sleep for worry at times which had a negative impact upon mood and ability to manage day to day (Female; 55-64; North East England; 15+ years since diagnosis).

The government has targeted sick and disabled people for benefit cutbacks and the system feels like it's set up with the assumption that we're all liars and benefit cheats. I live in fear of my benefits being taken away and knowing I'm physically incapable of working and supporting myself makes me feel very vulnerable. My options feel limited by being unable to support myself. I'm very grateful for the support I receive but there's a cost of being on disability benefits in terms of selfesteem and self-worth. Sometimes I wonder what the point of me is (Female; 45-54; London $15+$ years since diagnosis).

Our respondents' narratives suggest that systems of State support are fundamentally at odds with the complexity of conditions such as lupus despite the fact that, in 2013 , the UK Government recognised that assessments were not capturing the fluctuating nature of some long-term conditions and, in response, embedded new regulations into the assessment process (Gray, 2014, 2017) which should enable assessors to better take account of, and reflect, the variable nature of conditions such as lupus such that the assessment should determine

... whether an activity is completed reliably, safely, repeatedly and within a reasonable time period and whether the impairment affects claimants on the 
majority of days. This must also be done in a way that does not disadvantage any particular group of claimants such as those with fluctuating conditions, mental health conditions or learning disabilities (Gray, 2017:56).

\section{Discussion}

Despite the assurances that ought to be embedded in the initiative outlined above, respondents in our study clearly articulated the fact that 'fluctuation' (and its effects) is poorly understood and operationalised in the context of benefits claims. It remains, for many, an insurmountable hurdle in the battle to be recognised and accommodated both in and out of the workplace.

For the respondents in this study, the concept, and experience, of fluctuation, threads through, and effectively overshadows, people's experiences of claiming State benefits. The fluctuating nature of lupus, in particular, creates a shifting sense, and experience, of illness with a concomitant uncertain link to eligibility and entitlement of benefits. This ambivalence is compounded by a perceived requirement to accurately articulate and perform one's ongoing illness in both private and public arenas. Fluctuation inevitably mitigates against a consistent display and, when it comes to a claim for State support, this inconsistency, and its many effects, clearly mitigates against people's willingness to claim benefit, and their experiences within the benefits systems if they do so.

The lack of attention that is paid to issues of fluctuation generates a clear disincentive to making a claim and the ambivalence surrounding the experience of fluctuation meant that many respondents perceived themselves to be ineligible to claim and felt that they would, inevitably, be unsuccessful if they were to do so. Respondents often did not perceive themselves to be 'disabled enough' to claim and many actively resisted being defined in this way. Moreover, the fluctuating nature of lupus means that people were often able to work, just not consistently. Thus, we would strongly advocate for a recognition that, for some people, particularly those whose symptoms impact unpredictably on their ability to work from day to day, part-time work in combination with state benefits, may be the most appropriate (though, at present, patently inaccessible) approach to maintaining a person's ability to continue in paid employment, thus ensuring that their skills are not irrevocably lost to the workplace. 
Once reconciled to claiming State support, however, respondents referred to confusion and an evident reluctance to access welfare benefits which related, for many of our respondents, to the semantic distinctions that frame concepts of 'disability' and 'chronic illness', though there was, a clear distinction to be made between the two. Respondents perceived themselves to be 'disabled' by their condition, yet were not prepared, or able, to assume what they perceived to be a disabled identity.

In this context, we would argue that the experience of chronic illness has been, and continues to be, inadequately defined, within the disability and welfare benefits literatures, meaning that it is variously, and inconsistently, understood, both as concept and experience, by the range of actors associated with it. There is, therefore, an increasingly well-articulated argument for embedding the experience of chronic illness more purposefully within the lexicon of disability (a concept that is more reliably defined, understood and legislatively supported). There is, however, a very evident disjuncture in both the public and professional perception of what constitutes a chronic illness and whether, in fact, it does count as a 'disability' at all, given that the boundaries of what 'counts' as disability are simultaneously contestable, and, arguably, rigid which, in the context of fluctuating and invisible conditions, is patently unhelpful. The distinction between the two centres, primarily, upon the ways in which disability and chronic illness are variously mitigated by an attention to aspects of the physical environment (disability arguably is, whereas chronic illness is not, amenable to such accommodation). As such, "the divide between disability and illness is unclear; and the significance of the divide is disputed" (de Wolfe, 2012:618), some of the consequences of which manifest themselves in the experience of the assessment system.

Hale (2018) provides an historical analysis of the ways in which disability and chronic illness came to be separated, both semantically and experientially, as a result of a desire to sever the causal link between impairment and disability focusing, instead, on the impact of inadequate structural accommodations to impairment. Whilst this has clearly served the disability movement well, shifting attention to the inadequacy of legislative, policy-based and environmental responses to impairment, it had the paradoxical effect of obfuscating the experience of chronic illness, leaving it "outside the arena of politics and political action" (Hale, 2018:21). The contemporary disability movement has somewhat sidestepped the 
complex question of whether chronic illness constitutes disability by clearly recognising and acknowledging the realities of living with a chronic condition whilst simultaneously asserting that the issues associated with living with a chronic illness are outside of the disability movement's purview (de Wolfe, 2002).

We would suggest, however, both semantically and experientially that, whilst the distinctions between disability and illness will, undoubtedly, continue to be contested, there remains a lack of effective legislative and policy informed responses to the challenges faced by chronically ill people until there is a formal recognition that chronic illness constitutes and generates significant disability (though the two terms, are not necessarily analogous). What is required is a coming together of two ideologically similar, yet determinedly separate, movements to enable an effective political and social response to the significant challenges (in the workplace and elsewhere) faced by people living with chronic illness on a daily basis.

What chronically sick people would gain from this broadening of the disability movement is inclusion in a political forum in which they could begin to articulate their social needs, ranging from respect for their experience and endurance to material arrangements which would make their lives less difficult (De Wolfe, 2002:265).

The number of intervening years since De Wolfe (2002) suggested an alliance which would help to address some of the individual and structural challenges faced by people with disabilities and chronic illnesses has, however, been sufficient to suggest that these alliances are far from simple to conceptualise, construct and maintain. She herself evidences this in a recent blog (2018) posting where she argues that chronic illness would, in fact, not be well served by conflating it with disability.

'Disability' sounds so much more optimistic now that we have the social model. Just provide - not, of course, that anyone usually does but it's the principle of the thing the appropriate adaptations, and: problem solved! But with illness it's often more complex...

This is clearly complex ground, but one of our principal suggestions in this paper is for a concerted reinvigoration of the debate outlined above in order to afford the experience of 
chronic illnesses, such as lupus, their appropriate place in the lexicon of illness and disability. It is, after all, not just the limitations of a benefits system which does not manage to successfully negotiate the complexities of fluctuating conditions, but the fact that 'disability' is such a fixed, and seemingly inflexible, category. Conditions such as lupus are undeniably 'disabling', but variously so, therefore, models of disability which do not take account this variability are inevitably flawed. We would argue strongly, therefore, for a framework for conceptualising disability which takes cognisance of, and appropriately accommodates, the experience of fluctuation. A concerted focus on these issues might more effectively articulate the experience of living with a chronic illness with the legislative and policy driven processes and protections which are designed to enable as full and active a working life as possible, whatever the physical, psychological or social constraints a person may face. 


\section{References}

Allen, K., Hale, C., Seton, K. and Newton, J. 2016. A deeply dehumanising experience M.E./CFS journeys through the PIP claim process in Scotland. Online. [Available] https://www.actionforme.org.uk/uploads/pip-report-scotland.pdf (Accessed 15th August 2018)

Bambra, C. 2008. 'In Sickness or in Health? Incapacity Benefit Reform and the Politics of III Health'. British Medical Journal. 337: 1452-1453

Bambra, C. and Smith, K. E. 2010. 'No longer deserving? Sickness benefit reform and the politics of (ill) health'. Critical Public Health. 20(1) 71-83

Barnes, C. and Mercer, G. (Eds) 1996. Exploring the Divide: illness and disability. Leeds: Disability Press.

Booth, S., Price, E. and Walker, E. 2018. 'Fluctuation, invisibility, fatigue - the barriers to maintaining employment with systemic lupus erythematosus: results of an online survey'. Lupus. Online. [Available] https://doi.org/10.1177/0961203318808593 (Accessed January 4th 2019)

Braun, V. and Clarke, V. 2008. 'Using thematic analysis in psychology'. Qualitative Research in Psychology. 3(2) 77-101,

British Psychological Society. 2017. Ethics Guidelines for Internet-Mediated Research. Online. [Available] https://www.bps.org.uk/news-and-policy/ethics-guidelines-internetmediated-research-2017 (Accessed 28th August 2018)

Bury, M. 1982. Chronic Illness as Biographical Disruption'. Sociology of Health and Illness. 4: 167-182

Bury, M. 1991. 'The Sociology of Chronic Illness: A Review of Research and Prospects'. Sociology of Health and IIIness. 13: 451-486

Butler, P. 2018. 'Former watchdog chief labels disabled benefits process a 'hostile environment". The Guardian (6th October). Online. [Available] https://www.theguardian.com/society/2018/oct/06/former-watchdog-chief-labelsdisabled-benefits-process-a-hostile-environment (Accessed 22nd October 2018) 
Carel, H. 2008. Illness: The Art of Living. Durham: Acumen Publishing Limited

Charmaz, K. 1983. Good Days Bad Days: The Self in Chronic Illness and Time. New Brunswick: Rutgers University Press

Commons Select Committee. 2017. Web forum: PIP and ESA. Online. [Available] https://www.parliament.uk/business/committees/committees-a-z/commons-select/workand-pensions-committee/pip-esa-assessments-forum-17-19/

de Wolfe, P. 2002. 'Private Tragedy in Social Context? Reflections on Disability, Illness and Suffering'. Disability \& Society. 17(3) 255-267

de Wolfe, P. 2012. 'Reaping the benefits of sickness? Long-term illness and the experience of welfare claims'. Disability \& Society. 27(5) 617-630

Disabled People Against Cuts. 2017. PIP Assessment - Your Experience. Online. [Available] https://dpac.uk.net/2017/03/pip-assessment-experience/ (Accessed 20th August 2018)

Department for Work and Pensions, Department of Health. 2017. Improving lives. The future of work, health and disability. Online [available] www.gov.uk/government/publications (accessed 30th April 2018) Foubert, J., Levecque, K. and Van Rossem, R. 2016. 'Feeling well while chronically ill or impaired: a multilevel study on the moderating role of employment and volunteering in Europe'. Disability and Society. 32(1) 17-36

Garthwaite, K. 2011. 'The language of shirkers and scroungers?' Talking about illness, disability and coalition welfare reform. Disability \& Society. 26(3), 369-372

Garthwaite, K.; Warren, J. and Bambra, C. 2013. 'The unwilling and the unwell'? Exploring stakeholders' perceptions of working with long term sickness benefits recipients'. Disability \& Society. 28(8) 1104-1117

Garthwaite, K. 2014. 'Fear of the Brown Envelope: Exploring Welfare Reform with LongTerm Sickness Benefits Recipients' Social Policy and Administration. 48(7) 782-798 Garthwaite, K. 2015. 'Becoming incapacitated? Long-term sickness benefit recipients and the construction of stigma and identity narratives'. Sociology of Health \& IIIness. 37(1) 1-13 
Goffman, E. 1990. The Presentation of Self in Everyday Life. London: Penguin

Gray, P. 2014. An Independent Review of the Personal Independence Payment Assessment. Online [Available]

https://assets.publishing.service.gov.uk/government/uploads/system/uploads/attachment_ data/file/387981/pip-assessment-first-independent-review.pdf (Accessed 10th May 2018)

Gray, P. 2017. The Second Independent Review of the Personal Independence Payment. Assessment. Online [Available]

https://assets.publishing.service.gov.uk/government/uploads/system/uploads/attachment_ data/file/604097/pip-assessment-second-independent-review.pdf (Accessed 10th May 2018)

Hale, C. 2018. Reclaiming 'Chronic Illness': An introduction to the Chronic Illness Inclusion Project. Online [Available]

https://www.centreforwelfarereform.org/uploads/attachment/617/reclaiming-chronicillness.pdf (Accessed 15th July 2018)

Harris, J. 2017. 'It's just mistake after mistake' - stories from the universal credit catastrophe'. The Guardian. Online. [Available] https://www.theguardian.com/society/2017/nov/20/mistake-universal-credit-catastrophemisery (Accessed 16th October 2018)

Illich, I. 1974. 'Medical Nemesis'. The Lancet (reprint) Online. [Available] https://jech.bmj.com/content/57/12/919 (Accessed 12th October 2018)

Mail Online. 2013. 'I will go after bogus disabled... some of them DO get better! Ex-TV host who is our new Work Minister on the UK'S THREE MILLION claiming disability benefit'. Online [Available] https://www.dailymail.co.uk/news/article-2301735/l-bogus-disabled-DO-better-Ex-TV-host-new-Work-Minister-UKs-THREE-MILLION-claiming-disabilitybenefit.html (Accessed 1st December 2018)

Muscular Dystrophy UK. 2016. http://www.musculardystrophyuk.org/talkmd/topic/pipassessments/

Nettleton, S. 2013. The Sociology of Health and IIIness. 3rd ed. Cambridge: Polity Press. 
Parsons, T. 1951. The Social System. London: Routledge \& Kegan Paul Ltd

Pickles, C., Holmes, E., Titley, H. and Dobson, B. 2016. Working welfare: a radically new approach to sickness and disability benefits. London. Reform

Price, E. and Walker, E. 2014. 'Diagnostic vertigo: The journey to diagnosis in systemic lupus erythematosus'. Health 18(3):223-39

Price E. and Walker L. 2015. Chronic Illness, Vulnerability and Social Work: Autoimmunity and the Contemporary Disease Experience. Oxford: Routledge

Ravetz, A. 1998. 'When is a disability not a disability? When it's M.E.', in: C. March (Ed.) Knowing ME: women speak out about myalgic encephalomyelitis and chronic fatigue syndrome. London: Women's Press

Riach, K. and Loretto, W. 2009. 'Identity work and the 'unemployed' worker: age, disability and the lived experience of the older unemployed'. Work, Employment and Society. 23(1): $102-119$

Stockl, A. 2007. 'Complex Syndromes, Ambivalent Diagnosis, Existential Uncertainty: The Case of Systemic Lupus Erythematosus (SLE)'. Social Science and Medicine. 65(7) 1549-1559

Swain, J. and French, S. 2000. 'Towards an affirmation model of disability. Towards an affirmation model of disability'. Disability \& Society. 15, 569-582

Waddell, G. and Burton, A. K. 2006. Is Work Good for Your Health and Well-Being? Online. [Available]

https://assets.publishing.service.gov.uk/government/uploads/system/uploads/attachment_ data/file/214326/hwwb-is-work-good-for-you.pdf (Accessed 16th October 2018)

Wainwright, D., Wainwright, E., Black, R. and Kenyon, S. 2012. 'Reconstructing the self and social identity: new interventions for returning long-term Incapacity Benefit recipients to work'. In, S. Vickerstaff, C. Phillipson and R. Wilkie. 2012. Work, Health and Wellbeing: The Challenges of Managing Health at Work. University of Bristol: Policy Press

Walker, L. 2017. “There's no pill to help you deal with the guilt and shame': Contemporary experiences of HIV in the United Kingdom'. Health. Online. [Available] 
https://journals.sagepub.com/doi/abs/10.1177/1363459317739436 (Accessed 24th October 2018)

Warren, J., Garthwaite, K. and Bambra, C. 2013. 'After Atos Healthcare: is the Employment and Support Allowance fit for purpose and does the Work Capability Assessment have a future?' Disability \& Society. 29(8) 1319-1323

Williams, S. 2000. 'Chronic illness as biographical disruption or biographical disruption as chronic illness? Reflections on a core concept. Sociology of Health \& IIIness. Online. [Available] https://onlinelibrary.wiley.com/doi/abs/10.1111/1467-9566.00191 (Accessed 25th November 2018) 